\title{
A Research on the Cultivation System of Innovative Talents
}

\section{at Colleges}

\author{
Yurong Chen \\ School of Economics \& Management, Jiangsu Polytechnic University \\ Changzhou 213164, China \\ E-mail: cyrpzh@126.com
}

Foundation item: "A Research on Innovative Talent Cultivation at colleges in Jiangsu” (ZZKT09198) planned by Jiangsu Higher Education Academy, "A Research on Innovative Talent Cultivation at Colleges in the Science and Education City” (K2009202) supported by the Scientific Research Foundation of Universities in Changzhou Science and Education City.

\begin{abstract}
As an important part in the national innovation system, colleges are the cradle for innovative spirits and talents as well as the main base for the innovation, transmission and application of knowledge. Therefore, they are expected to be adapted to the demands of social and economic development, to update their education ideas, to actively promote innovative education and to explore basic patterns and fundamental channels of innovative talent cultivation.
\end{abstract}

Keywords: Innovative talents, Cultivation System, Innovative education

Universities and colleges play an important role in implementing the national strategy of independent innovation and the construction of an innovative nation due to their responsibilities of cultivating talents during the course. Accordingly, they are expected to innovate their educational researches, to reform their talent cultivation patterns, to actively explore effective channels of innovative talent cultivation and to establish suitable cultivation system as soon as possible, which are not only the objective demands to construct an innovative nation but necessary choices for their own development.

\section{Basic Qualities of Innovative Talents}

Here innovative talents refer to those with innovative spirits, innovative thoughts and abilities, innovative achievements as well as sense of innovation. They tend to be quickly aware of changes and tendencies in their surroundings, then to put forward new ideas or things. Generally speaking, they are endowed with some internal qualities including innovative invention, scientific research, organization and management, coordination and learning as well as analysis and judgment. With some opinions from the domestic and foreign academic community summarized, the following basic qualities should be included:

\subsection{Tough Innovative Will}

Innovation is a process of exploring unknown fields and reforming known ones with great difficulties, frustrations or even failures. Only with remarkable courage, perseverance and the capacity to face up to failures and frustrations will innovative talents be able to conquer all kinds of difficulties and accomplish satisfactory effects.

\subsection{Innovative Spirits to Explore}

Innovative talents must be endowed with dedicated spirits, strong career ambition and sense of responsibility, which are the internal drive, the potential and the fundamental guarantee for people's innovative abilities and activities.

\subsection{Acute Observation}

Innovation, by nature, is a ground-breaking discovery. As is required, innovative talents are expected to have acute observation, profound insight, sharp intuition and inspiration to connect the things they have observed with the knowledge they have mastered, to find out the indispensable connection among things and to discover things undetected by others.

\subsection{Active Innovative Thoughts}

Innovative talents must have prospective, flexible and original thoughts, hence guaranteeing their unique analysis, summary and judgment as well as new and unique thoughts of social value. 


\subsection{Rich Innovative Knowledge}

Innovation, the development of the existing knowledge, requires a wide and deep knowledge structure, deep and solid basic knowledge about some neighboring subjects and necessary interdisciplinary knowledge, the mastery of one's specialty and the latest achievements and development of his subject because such a complete knowledge structure helps to enhance his comprehensive thinking and innovative abilities.

\subsection{Scientific Innovative Practice}

Innovation is also a process to explore based on science and the objective laws of the world. Accordingly, innovative talents must have truth-seeking attitudes toward their jobs and tight logic to guarantee exact analysis, judgment and mastery of the objective laws of the world and to have innovative practice with scientific spirits.

\section{Educational Ideas of Cultivating Innovative Talents}

\subsection{The Idea of Imparting Knowledge and Educating People}

Innovative talents should be those with an all-round development of morality, intelligence, physique and art. Therefore, in innovative education, the establishment of students' right outlooks on life, world and value should be put to the top and greater emphasis should be put on cultivating students' patriotism, honesty, responsibility as well as carving out, cooperation and dedication, enhancing students' physical and mental health and humane and art education and cultivating their healthy personalities. In order to achieve these goals, we should stick to the idea of imparting knowledge and educating people and regard the cultivation of innovative talents as the most important among teachers' responsibilities, strengthen teachers' sense of responsibility and professional ethics to conduct their teaching and improve their teaching level, encourage more excellent teachers to be devoted to studying and conducting innovative education by having more professors hold lectures and creating a profound atmosphere respecting, loving and enjoying teaching.

\subsection{The Idea Emphasizing Innovation}

Innovative education has innovation as its core and practice as its basis. With Practice as the basis, college education is expected to reflect the latest achievements of social economic development, to strength practical sections to develop students' practical abilities and to have a combination of production, education and research. With innovation as the core, college education is expected to input innovative sense, innovative thoughts and innovative spirits into students' minds and to cultivate innovative abilities through practical teaching and practice.

\subsection{The Idea Centering on Students}

With students as the main body of innovative talent cultivation, their central status must be stuck to, the principle of individualized instruction based on students and the development rule of innovative talents should be followed to construct an innovative talent cultivation system guided by "individualized learning" and to stimulate students' passions and potentials for innovation. According to their learning interest and ability, students should be helped to confirm their specialties independently, to design their knowledge structure and choose their learning ways independently. In this way, they will fully enjoy their independent learning and fully exert their enthusiasm and activity during the learning process, hence offering necessary conditions and expanding space for their independent cultivation of innovative abilities.

\subsection{The Idea Aiming at Success}

It is the responsibility of teachers, the duty of schools as well as the purpose of education to guide students to achieve their success. As is required by the aim at success, the fundamental task of innovative talent cultivation should be centered on in the implementation of all tasks, the construction of teaching and learning spirits should be held to improve teaching quality, students should be encouraged to spend more time and energy on innovative learning and practice. To sum up, such an idea means practicing innovative education all through all sections of teaching, research and administration at colleges.

\section{Basic Patterns of Innovative Talent Cultivation}

\subsection{Combining Guidance with Self-Learning through the Interactions between Teachers and Students}

In innovative education, students are the main body and teachers are the leader. Therefore, an interactive atmosphere should be created to exert students' activity for creative learning and teachers' leading role in creative teaching.

Teachers' creative teaching is mainly reflected in their educational ideas, contents and teaching methods. They are expected to regard students as equal educational subjects, to choose and design their education process 
starting from the aim of students' all-round development and individuality development, hence encouraging students to acquire knowledge and improve ability actively and creatively. Meanwhile, teachers should keep track of the latest information on scientific and technological development and achievements in education, science and technology and embody them into their teaching contents, stimulate students' interest in learning, cultivate their confidence, courage and exploratory spirits and inspire their innovative thoughts and behaviors through advanced teaching methods and delicate teaching arts.

Students' creative learning is mainly reflected in their purposeful, industrious and creative learning. Clear purposes will promote their progress in learning. Students should bear it in mind that they are expected to learn how to learn as well as to master knowledge through their learning, that they learn not only for themselves but for the society and learning is a process filled with hardship requiring struggling spirits to make advance regardless of difficulties. In addition, students should have creative learning in order to cultivate their innovative thoughts and abilities and to deal with their future jobs.

\subsection{Emphasizing Both Theory and Practice and Combining Knowledge with Its Application}

With no doubt, innovative talents must be equipped with solid professional theory foundation. However, over-emphasis on the consistence, systematicness and completeness of knowledge as well as students' wide range of basic knowledge will necessarily lead to their excessive burden and affect the development of their innovative abilities and spirits. Correspondingly, the current educational pattern must be reformed and students' curiosity, imagination, intuition and insight should be based on to optimize the curriculum system and the knowledge structure, to expand their range of knowledge, to enhance practical teaching, to stick to the principle of emphasizing both theory and practice to combine knowledge with its application in the design of development plans and teaching schemes and to carefully organize theoretical and practical teaching based on the fundamental goal of cultivating students' innovative spirits and abilities of solving practical questions.

In addition, the right value orientation must be stuck to in the cultivation of innovative talents, according to which students shouldn't be evaluated only according to their grades but according to their practical abilities (abilities of applying theoretical knowledge to problems). As a result, new viewpoints related to education, talents and quality adaptable to the need of era should be established and an institutional environment encouraging innovation, understanding failure and rewarding success should be formed by innovating evaluation system and normalizing evaluation actions.

\subsection{Emphasizing Both Class Education and After-Class Education and Combining On-Campus and Off-Campus Education}

School education can be mainly conducted in and out of class. Class education attaches greater importance to systematic knowledge, hence the main channel for students' learning while after-class education is mainly realized through after-class activities which emphasizes more on the cultivation of students' abilities of applying theories and acquiring knowledge and therefore is an enhancement and implementation for class education. This principle will help us to eliminate the one-sided view that innovative education only means strengthening after-class education as well as to get over the harmful trends that emphasize class education while neglecting after-class education, hence promoting the cultivation of students' innovative spirits and abilities.

On the other hand, from the perspective of the changes of colleges' functions, higher education has stepped from the edge of the society to its center and colleges have become an open platform for knowledge transmission and innovation instead of an isolated ivory tower with the arrival of the era of knowledge economy. As the cradle for innovative talents, colleges must offer open education. The combination of on-campus and off-campus education can not only reflect the openness of education but create favorable atmosphere for innovative education which helps to transform innovative education into a combination of on-campus and off-campus practice.

\section{Basic Paths of Innovative Talent Cultivation}

\subsection{Establishing Advanced Innovative Education Culture}

Cultural views exert remarkable influences on talent cultivation. In spite of its extensive and profound content, Chinese traditional culture has negative impacts on innovative education. For example, in Confucian classics and the moderate culture closely related to Chinese education, enlightenment is encouraged while being too conspicuous and showing doubt are forbidden, hence discouraging students from pioneering and exploration. With negation, criticism and surpass embodied in it, innovation is against obedience and unification. Therefore, in order to cultivate innovative talents, first of all, we should be brave enough to surpass these obstructive traditional cultures in our value attitudes and cultural emotions, that is, to establish a loose, energetic and active 
human environment on campus helpful for innovative talent cultivation.

\subsection{Constructing Innovative Teaching Staff}

The teacher plays a key role in innovative education quality. There is no innovative talent without teachers with innovative spirits. Therefore, greater importance should be attached to the construction of teaching staff in order to form a competition system beneficial for teachers' development. Relevant training should be strengthened to equip them with strong sense and idea of innovative education, with wide range of knowledge and reasonable knowledge structure as well as remarkable innovative abilities in teaching and research. It is through innovative teachers' teaching that innovative ideas can be implemented all through the whole teaching process or even the whole education process.

\subsection{Creating Institutional Environment Beneficial for Innovative Talent Cultivation}

The cultivation of innovative talents also relies on institutional innovation. Compared with developed countries, Chinese higher education suffers from insufficient energy for innovation. In order to solve this problem fundamentally, great efforts should be made in institutional construction to reform old educational administration institution and talent cultivation patterns, to actively construct institutional system beneficial for innovative talents' growth. In addition, institutional restrictions should be broken in innovating the academic organizations in university to achieve the organic combination and interaction between teaching and research and to create high-level teaching with high-level research; comprehensive reforms should be conducted in enrollment and cultivation to constantly improve talent selection systems and cultivation patterns; innovation education should be promoted through institutional guarantee to promote the cultivation of students' creativity and personality.

\subsection{Constructing Innovative Talent Cultivation System Emphasizing Both Teaching and Research}

Teaching and research are expected to be combined organically to fully exert the research advantages of universities and therefore to make it inexhaustible resource and environment. First, teachers need to be qualified in both teaching and research. With modern universities having the functions of knowledge innovation, application as well as convey, teachers cannot melt the knowledge they acquire and innovate in innovative activities into their curriculum system and teaching process or cultivate students' abilities in acquiring knowledge and solving problems with their ideas of scientific and technological innovation without their devotion to research. Second, innovation platforms and optimized curriculum system with the combination of teaching and research should be constructed. Besides the undergraduate stage, the cultivation of innovative talents should also go through longer periods including postgraduate and even post-doctoral stages. However, undergraduate education is an important basis, during which general education and the cultivation of practical and independent abilities should be enhanced. Therefore, greater importance should be attached to constructing innovative platforms and optimizing knowledge structure, to achieving the conversion from "the cramming method" to "the elicitation method" and to changing students' role from accepting knowledge passively to acquiring knowledge actively. Finally, the cultivation of humanistic and scientific spirits should also be included in the innovative talent cultivation system because they are both the basis for one's success and the soul of a university.

\subsection{Enhancing Innovative Education Practice and Teaching Quality Monitoring}

In innovative education, equal teacher-student relationship must be established to drive innovative talent cultivation on the premise of innovative teachers. Students should be given fundamental consideration during the teaching process and more emphasis should be given to teaching students how to learn, encouraging their activity in independent learning and cultivating students' independent learning abilities in many aspects; students' imagination should be stimulated to cultivate their innovative thoughts and innovation should be encouraged through giving demonstrations, activating teaching methods and having comparisons; students' individuality should be respected and encouraged to fully display their strengths by having innovation during the imitation process.

Teaching is the key to innovative education. Therefore, an all-round teaching quality monitoring system should be established to serve the core of innovative education effectively; the administration on monitoring feedback information should be enhanced to fully exert the active role of feedback information in improving teaching quality; a variety of encouragement methods should be used comprehensively to give encouragements in different forms to those teachers and students with remarkable performance in innovative education practice.

\section{References}

Chen, Changgui \& Weng, Lixia. (2008). The Globalization of Higher Education and the Cultivation of Innovative Talents. Higher Education Researcch. (6). 
Han, Lijuan. (2007). On the Cultivation of Innovative Talents in University in the Condition of Knowledge Economy. Education Exploration. (7).

Li, Guoqiang. (2007). Constructing Innovative Talent Cultivation System to Improve Innovative Abilities. China Higher Education. (10).

Peng, Xiaobo. (2008). A Research on Innovation Education and Innovative Talent Cultivation. Henan Social Science. (3).

Xu, Xiaozhou. (2007). Constructing Theory and Institution of Innovative Talent Cultivation: A Case in Zhejiang University. China Higher Education Research. (9).

Zhou, Ji. (2006). Emphasizing Innovative Talent Cultivation and Strengthening High-Level Innovative Abilities in University. China Higher Education. (15/16). 